\title{
Classification of Immature and Mature Coffee Beans Using HSV Features and Machine Learning Algorithms
}

\author{
Larry B. de Guzman \\ College of Computing Science, Information and Communication Technology, Isabela State University, \\ Echague, Isabela , Philippines, deguzman.larry.b@gmail.com
}

\begin{abstract}
This paper separates immature from mature coffee beans using the hue, saturation and brightness values (HSV). It was proven in another paper that red, green, and blue (RGB) values differs in mature and immature coffee beans so the author thought of using HSV values to separate the two bean groups. The HSV values were extracted using image processing and machine learning algorithms were used in classification. The MATLAB Classification Learner App containing 23 different machine learning algorithms was used in discriminating between mature and immature coffee beans. The medium Gaussian support vector machine achieved the highest classification accuracy of $94 \%$ at 0.14624 seconds.
\end{abstract}

Key words : Immature coffee beans; Average Hue, Average Saturation, Average Values; Medium Gaussian SVM

\section{INTRODUCTION}

Coffee is a beverage obtained from cherry, the fruit of coffee plant. The coffee plant refers to several species of the genus coffee of the Rubicaecea family, which is actually a tropical evergreen shrub that has the potential to grow to a height of 100 feet [1]. Due to its idiosyncratic smell and taste, the coffee plant has been represented as an essential part of special moments. Coffee, is known to have approximately 70 types is a well received, in demand drink and is a very significant commodity worldwide. Millions of small-scale farmers in developing countries are dependent in coffee farming as their major source of income. All over the world, there are 2.5 billion cups of coffee being consumed in a daily basis. While farming is done in developing countries, it is the industrialized countries that does most of the consumption. Green coffee beans is one of the most traded agricultural product in the world second to oil. Coffee sustained the economies of developing countries as it is considered as a major source of their foreign exchange [2]-[4]. Coffee cherries should only be harvested when they are fully red in the branches. However, coffee cherries do not ripen at the same time. Some cherries are fully red while other cherries are yellow and others remain green. Farmers should harvest the red cherries and wait for yellow and green beans to mature and become fully red. Because red, yellow and green coffee cherries when harvested and dried are indistinguishable from one another. Farmers opted to save money and harvest the cherries whether they are red, yellow or green[5]. While mature and immature beans are almost the same in the naked eye they are totally different in taste. The presence of immature coffee lowers the quality and also lowers the price of coffee beans[6,7].

This study builds on the previous research done in immature and mature coffee beans [5] and answers the research question, "Which color features, RGB or HSV values is best in discriminating mature and immature coffee beans?" To compare which color feature is the best, this study also extracted the HSV using image processing and then subjected the extracted features for classification using the machine learning algorithms.

HSV is another format of how an RGB colors can be represented. Hue is the property of light that discriminates one color to other colors, for example the yellow color from brown or pink. Saturation is the level of white of a light source in an image. Values or brightness values is how intense the brightness of an image[8]. Image processing is a technique to carry out a particular procedures on an image so that a more refine, upgraded image would result or to extract useful features from an image[9-24].

The MATLAB Classification Learner App contains 23 machine learning classifiers. The extracted data thru image processing or any other type of data composed of numerical values are used as input. The App trains the data and validates the classification in terms of accuracy and training speed[24-27].

\section{METHODOLOGY}

\subsection{Coffee Samples}

The coffee beans used in this study is from the harvest season of coffee in the Philippines in the year 2019. These coffee beans were stored for a year with husks still on them and this March 2020, the husks were remove and used as samples in this study. There are two groups namely the mature coffee beans and the immature coffee beans from the Robusta specie. A total of 100 mature coffee beans and 100 immature coffee beans were used. 


\subsection{Feature Extraction}

Upon visual inspection even an untrained eyes can see that there are differences in color between mature and immature coffee beans. The problem is when the two groups were mixed. Separating one from the other becomes a problem. It was confirmed in the previous study that mature and immature coffee beans differ in terms of RGB color values[5]. This study is further exploiting more deeply if the HSV color features can also differentiate mature and immature coffee beans because HSV is based in RGB. The HSV values were derived from the RGB values as related by the formula shown in Figure 1.

$$
\begin{aligned}
& H=\arccos \left\{\frac{\left[\frac{(R-G)+(R-B)}{2}\right]}{(R-G)+\sqrt{(R-B)(G-B)}}\right\} \\
& S=1-\frac{3}{(R+G+B)}[\min (R, G, B)] \\
& V=\frac{1}{3}(R+G+B)
\end{aligned}
$$

Figure 1 : Relation of HSV to RGB

It can be seen in Figure 1 that HSV values were derived from RGB values.

The set-up for taking of images was made an exact duplicate of [5]. The coffee beans were pictured using an A4tech PK-835 G webcam at the height of $13.5 \mathrm{~cm}$ with 2 LED strips at the side of the camera that are 2 inches apart. The HSV features were extracted using the Python program.

\section{RESULTS AND DISCUSSION}

Table 1 shows the values of HSV color, extracted through image processing.

Table 1 shows that values of hues, saturation and brightness for mature and immature coffee beans are overlapping to one another. By using a classifier the author discriminated which one is mature and which one is an immature coffee bean.

The classifier used are the 23 machine learning algorithms of MATLAB Classification Learner App. The 100 beans were used as inputs at once and the settings was chosen to be 5 folds. This means that 80 percent will be used as training samples. Five folds is the total number of samples per class divided 5, that is 100 divided 5 equals 20. A total of 80 samples were used as training samples and 20 samples were used as test samples. The result of classification is shown in Table 2.

Table 1: Extracted HSV values for Mature and Immature Coffee beans

\begin{tabular}{|c|c|c|}
\hline Classifier Type & $\begin{array}{l}\text { Accuracy } \\
(\%)\end{array}$ & $\begin{array}{l}\text { Training Time } \\
\quad \text { (Seconds) }\end{array}$ \\
\hline Fine Tree & 89 & 9.725 \\
\hline Medium Tree & 89 & 0.16565 \\
\hline Coarse Tree & 93 & 0.15127 \\
\hline $\begin{array}{c}\text { Linear } \\
\text { Discriminant }\end{array}$ & 91.5 & 1.9528 \\
\hline $\begin{array}{c}\text { Quadratic } \\
\text { Discriminant }\end{array}$ & 92 & 0.49839 \\
\hline $\begin{array}{l}\text { Logistic } \\
\text { Regression }\end{array}$ & 92 & 7.0282 \\
\hline $\begin{array}{c}\text { Linear Support } \\
\text { Vector Machine } \\
\text { (SVM) }\end{array}$ & 93.5 & 2.2795 \\
\hline Quadratic SVM & 94 & 0.20495 \\
\hline Cubic SVM & 93 & 0.38023 \\
\hline $\begin{array}{c}\text { Fine Gaussian } \\
\text { SVM }\end{array}$ & 91.5 & 0.17618 \\
\hline $\begin{array}{c}\text { Medium Gaussian } \\
\text { SVM }\end{array}$ & 94 & 0.14624 \\
\hline $\begin{array}{c}\text { Coarse Gaussian } \\
\text { SVM }\end{array}$ & 93 & 0.13773 \\
\hline Fine KNN & 83 & 1.2831 \\
\hline Medium KNN & 93.5 & 0.15308 \\
\hline Coarse KNN & 87 & 0.14464 \\
\hline Cosine KNN & 92 & 0.25553 \\
\hline Cubic KNN & 93 & 0.17559 \\
\hline Weighted KNN & 88.5 & 0.19314 \\
\hline Boosted Trees & 87 & 3.6323 \\
\hline Bagged Trees & 89 & 2.3021 \\
\hline $\begin{array}{c}\text { Subspace } \\
\text { Discriminant } \\
\end{array}$ & 91 & 1.7819 \\
\hline Subspace KNN & 86.5 & 1.5994 \\
\hline RUS Boosted Trees & 83.5 & 2.1379 \\
\hline
\end{tabular}

\begin{tabular}{|c|c|c|c|}
\hline $\begin{array}{c}\text { Coffee Bean } \\
\text { Type }\end{array}$ & $\begin{array}{c}\text { Average } \\
\text { Hue }\end{array}$ & $\begin{array}{c}\text { Average } \\
\text { Saturation }\end{array}$ & $\begin{array}{c}\text { Average } \\
\text { Value } \\
\text { (Brightness) }\end{array}$ \\
\hline $\begin{array}{c}\text { Mature } \\
\text { Coffee Beans }\end{array}$ & 127 to 155 & 45 to 71 & 94 to 173 \\
\hline $\begin{array}{c}\text { Immature } \\
\text { Coffee Beans }\end{array}$ & 100 to 147 & 41 to 71 & 110 to 177 \\
\hline
\end{tabular}

Table 2: Classification Results 
Figure 2 shows the scatter plot of the Medium Gaussian SVM for mature and immature coffee beans. The mature coffee beans were represented by the orange colors and the immature coffee beans as the blue colors. It can be seen in Figure 2 that HSV values of the two groups are separable in the viewpoint of the Medium Gaussian SVM.

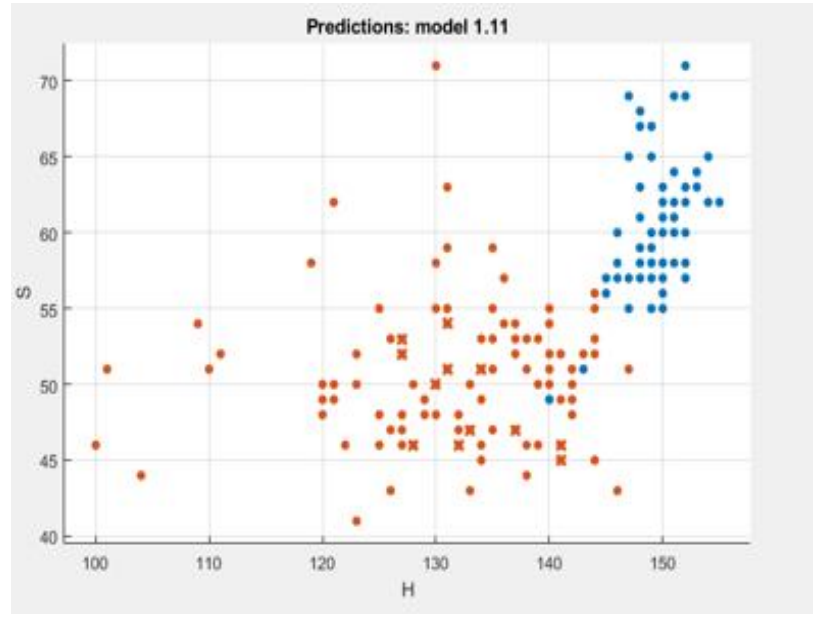

Figure 2 : Scatterplot of Medium Gaussian SVM

There are 2 classifiers that yielded the highest accuracy of $94 \%$ namely the Quadratic SVM and the Medium Gaussian SVM. Among these 2, the Medium Gaussian SVM has the fastest training time of 0.14624 seconds. Among 40 samples of mixed mature and immature coffee beans it will only take 0.14624 seconds to differentiate one class from the other. Even an expert human classifier will not be able to match that accuracy and speed.

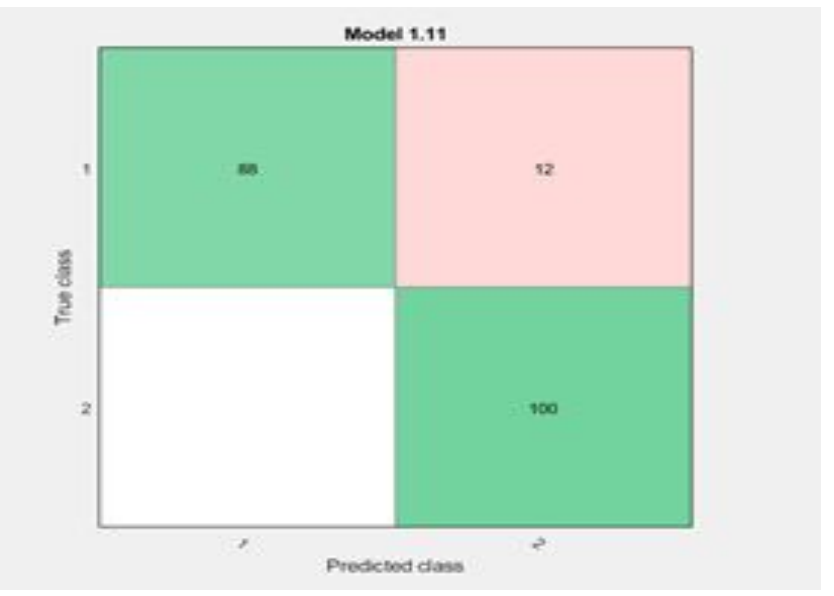

It can be seen in Figure 3 that for the Medium Gaussian SVM has 12 wrong classifications for mature coffee beans and 100 percent classification for immature coffee beans. This means that the HSV values for immature coffee beans can be identified by Medium Gaussian SVM while the same algorithm has an error when it comes to identifying the HSV features of a mature coffee beans.

Figure 4 shows the ROC or the receiver operating characteristics of the Medium Gaussian SVM.

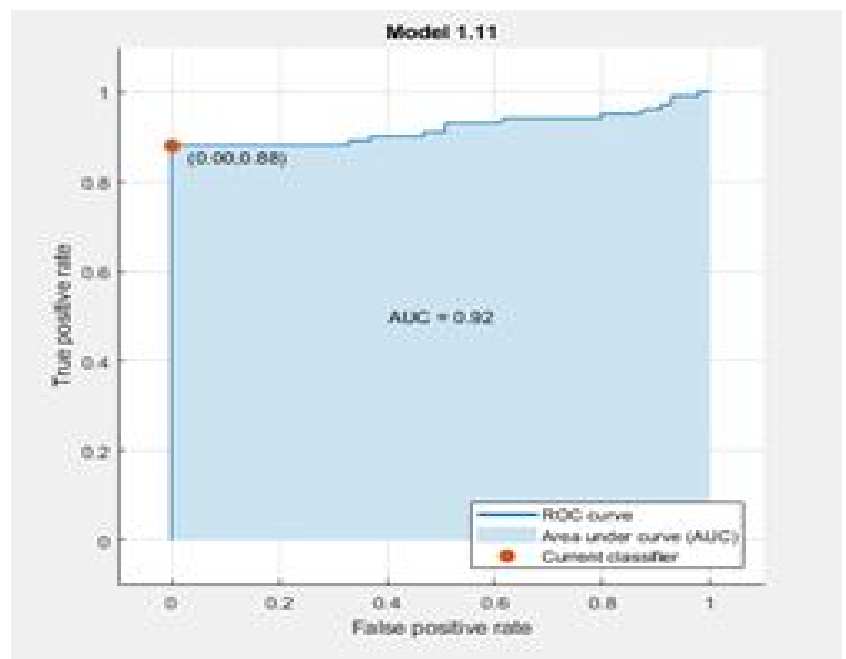

Figure 4: The ROC Curve of Medium Gaussian SVM

The receiver operating characteristic curve shows the relationship of the inputted features to the classifier. It can be seen in the Figure 4 that the area under the curve is 0.92 , this indicates that there is a higher percentage of classification using the inputted features.

Figure 5 shows the parallel coordinates plot of the Medium Gaussian SVM. It can be seen in Figure 5 that HSV values for mature coffee beans (orange color) is below those of the immature coffee beans (blue color). Although the values were overlapping, the Medium Gaussian SVM was able to differentiate between the two classes.

Figure 3: Confusion Matrix of Medium Gaussian SVM 


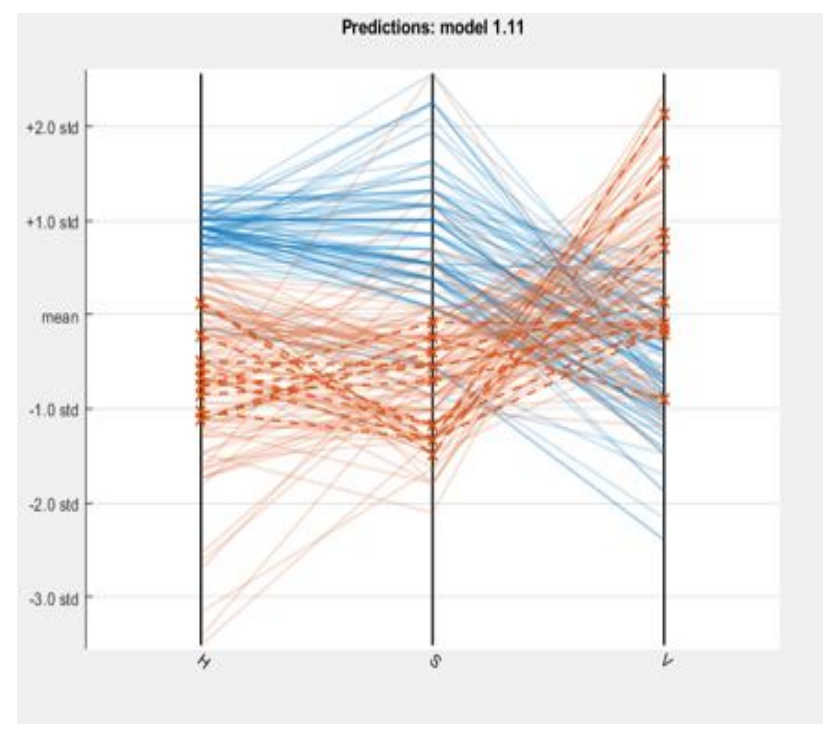

Figure 5: Parallel Coordinates Plot of the Medium Gaussian SVM.

Table 3 compares this study from the previous study.

Table 3: Comparison of Results

\begin{tabular}{|c|c|c|c|c|}
\hline Study & Fea- & $\begin{array}{c}\text { Classifie } \\
\text { tures }\end{array}$ & $\begin{array}{c}\text { Accurac } \\
\mathbf{y}\end{array}$ & Training Time \\
\hline $\begin{array}{c}\text { Previous } \\
\text { Study[5] }\end{array}$ & RGB & $\begin{array}{c}\text { Quadratic } \\
\text { SVM }\end{array}$ & $94 \%$ & 0.62 seconds \\
\hline This & HSV & $\begin{array}{c}\text { Medium } \\
\text { Gaussian } \\
\text { SVM }\end{array}$ & $94 \%$ & 0.14624 seconds \\
\hline
\end{tabular}

Table 3 shows the comparison of the previous study [5] to this study. In the previous study that uses RGB as features for classification, an accuracy of $94 \%$ was achieved by Quadratic SVM while in this study that uses HSV, an accuracy of $94 \%$ was also achieved by Medium Gaussian SVM. The two differs in terms of speed, the previous study can achieved 94\% accuracy at 0.62 seconds and this study can do it in 0.14624 seconds.

\section{CONCLUSION}

The research question being answered in this study is which color features, RGB or HSV is better to use for classification of immature and mature coffee beans. Although the classification accuracy of $94 \%$ is the same between [5] and this study, this study achieved faster training time. It can be concluded that in order to discriminate mature from immature coffee beans it is better to use the HSV features because it is 4 times faster compared to using the RGB features.

\section{REFERENCES}

[1] M. Murphy and T. J. Dowding, "The Coffee Bean: A Value Chain and Sustainability Initiatives Analysis," pp. 1-19, 2017.

[2] K. P. P. Nair, "6-Coffee," in The Agronomy and Economy of Important Tree Crops of the Developing World, Elsevier, 2010, pp. 181-208.

[3] A. Farah and T. Ferreira, "The Coffee Plant and Beans: An Introduction," in Coffee in Health and Disease Prevention, V. R. Preedy, Ed. Academic Press, 2015, pp. 5-10.

[4] M. Firmin, "From Bean to Cup : a history of coffee," 2014.

[5] W. R. Eustaquio and J. L. Dioses Jr., "Classification of Immature and Mature Coffee Beans Using RGB Values and Machine Learning Algorithms," Int. J. Emerg. Trends Eng. Res., 2020.

https://doi.org/10.30534/ijeter/2020/22872020

[6] E. R. Arboleda, A. C. Fajardo, and R. P. Medina, "An Image Processing Technique for Coffee Black Beans Identification," in 2018 IEEE International Conference on Innovative Research and Development (ICIRD), 2018, no. May, pp. 1-5.

[7] J. N. C. Sarino, M. M. Bayas, E. R. Arboleda, E. C. Guevarra, and R. M. Dellosa, "Classification Of Coffee Bean Degree Of Roast Using Image Processing And Neural Network," Int. J. Sci. Technol. Res., vol. 8, no. 10, pp. 3231-3233, 2019.

[8] E. R. Arboleda, A. C. Fajardo, and R. P. Medina, "Green coffee beans feature extractor using image processing," TELKOMNIKA (Telecommunication Comput. Electron. Control., vol. 18, no. 4, p. 2027, 2020.

[9] J. S. Kumari and U. R. Nelakuditi, "Gestation Age Determination through Optimized Fuzzy Logic Based Edge Detection Algorithm in Fetal Ultrasound Images," Int. J. Adv. Trends Comput. Sci. Eng., vol. 9, no. 3, pp. 3057-3068, 2020. https://doi.org/10.30534/ijatcse/2020/87932020

[10] A. E. Andaya, E. R. Arboleda, A. A. Andilab, and R. M. Dellosa, "Meat Marbling Scoring Using Image Processing with Fuzzy Logic Based Classifier," Int. J. Sci. Technol. Res., vol. 8, no. 08, pp. 1442-1445, 2019.

[11] J. G. C. Rancapan, E. R. Arboleda, J. L. Dioses Jr, and R. M. Dellosa, "Egg Fertility Detection Using Image Processing And Fuzzy Logic," Int. J. Sci. Technol. Res., vol. 8, no. 10, pp. 3228-3230, 2019.

[12] R. A. Magbayao, E. R. Arboleda, and E. M. Galas, "Identification Of Asian Green Mussel Perna Viridis ' Sex Using Image Processing, Fuzzy Logic And K - Nearest Neighbor," Int. J. Sci. Technol. Res., vol. 9, no. 01, 2020.

[13] C. I. A. Baluran, E. R. Arboleda, M. G. Dizon, and 
Larry B. de Guzman, International Journal of Emerging Trends in Engineering Research, 8(8), August 2020,4350 - 4356

R. M. Dellosa, “Crab Gender Classification Using Image Processing, Fuzzy Logic And K Nearest Neighbor ( KNN ) Classifier," Int. J. Sci. Technol. Res., vol. 8, no. 10, pp. 1458-1462, 2019.

[14] V. M. D. Manalo, E. R. Arboleda, J. L. D. Jr, and R. M. Dellosa, "Differentiation Among Lettuce ( L . Sativa ) Seed Varieties Grown In Gourmet Farms , Silang Cavite, Philippines Using Image Processing With Fuzzy Logic And Knn As Classifiers," Int. J. Sci. Technol. Res., vol. 8, no. 10, pp. 8-11, 2019.

[15] R. E. T. Bae, E. R. Arboleda, A. Andilab, and R. M. Dellosa, "Implementation Of Template Matching, Fuzzy Logic And K Nearest Neighbor Classifier On Philippine Banknote Recognition System," Int. J. Sci. Technol. Res., vol. 8, no. 08, pp. 1451-1453, 2019.

[16] V. A. C. Austria, E. R. Arboleda, and E. M. Galas, "Image Processing Of Clean And Dirty Dishes To Design And Construct A Fuzzy Logic Dishwasher," Int. J. Sci. Technol. Res., vol. 8, no. 12, pp. 8-11, 2019.

[17] J. A. A. Garcia, E. R. Arboleda, and E. M. Galas, "Identification Of Visually Similar Vegetable Seeds Using Image Processing And Fuzzy Logic," Int. J. Sci. Technol. Res., vol. 9, no. 02, pp. 4925-4928, 2020.

[18] F. B. Vidad III, E. R. Arboleda, J. L. Dioses Jr, and R. M. Dellosa, "Morphological Based Seedling Comparison Of Natural And Hybrid Lemon," Int. J. Sci. Technol. Res., vol. 9, no. 02, 2020.

[19] E. J. Olaes, E. R. Arboleda, J. L. D. Jr, and R. M. Dellosa, "Bell Pepper And Chili Pepper Classification: An Application Of Image Processing And Fuzzy Logic," Int. J. Sci. Technol. Res., vol. 9, no. 02, pp. 4833-4839, 2020.

[20] C. L. Macalalad, E. R. Arboleda, A. A. Andilab, and R. M. Dellosa, "Morphological Based Grain Comparison of Three Rice Grain Variety," Int. Jounal Sci. Technol. Res., vol. 8, no. 08, pp. 1446-1450, 2019.

[21] E. R. Arboleda, A. C. Fajardo, and R. P. Medina, "Classification of Coffee Bean Species Using Image Processing , Artificial Neural Network and K Nearest Neighbors," in 2018 IEEE International Conference on Innovative Research and Development (ICIRD), 2018, no. May, pp. 1-5.

[22] D. L. Bersabal, E. R. Arboleda, and E. M. Galas, "Coffee Bean Recognition Using Shape Features Using Decision Trees And Ensemble Classifiers," Int. J. Sci. Technol. Res., vol. 9, no. 02, 2020.

[23] A. J. G. Gonzales, J. A. D. Sosa, E. R. Arboleda, and E. M. Galas, "Filtering Of Faded Coffee Beans Using Image Processing," Int. J. Sci. Technol. Res., vol. 8, no. 12, pp. 3634-3637, 2019.

[24] A. M. Castillo, R. D. Aradanas, E. R. Arboleda, A. A. Dizon, and R. M. Dellosa, "Coffee Type Classification Using Gray Level Co- Occurrence Matrix Feature Extraction And The Artificial Neural Network Classifier," Int. J. Sci. Technol. Res., vol. 8, no. 10, pp. 1463-1465, 2019.
[25] E. R. Arboleda, "Comparing Performances of Data Mining Algorithms for Classification of Green Coffee Beans," Int. J. Eng. Adv. Technol., vol. 8, no. 5, pp. 1563-1567, 2019.

[26] E. R. Arboleda, "Discrimination of civet coffee using near infrared spectroscopy and artificial neural network," Int. J. Adv. Comput. Res., vol. 8, no. 39, pp. 324-334, 2018.

[27] J. L. Dioses, "Discrimination of civet coffee using image processing and machine learning," Int. J. Emerg. Trends Eng. Res., vol. 8, no. 4, pp. 1067-1072, 2020. https://doi.org/10.30534/ijeter/2020/19842020

[28] J. L. Dioses, "Classification of pepper seeds using data mining algorithms," Int. J. Adv. Trends Comput. Sci. Eng., vol. 9, no. 2, pp. 1460-1464, 2020.

https://doi.org/10.30534/ijatcse/2020/84922020

\section{APPENDIX}

Data Set of the Study

$\begin{array}{ccccc}\text { Sample } & & & & \\ \text { No. } & \mathrm{H} & \mathrm{S} & \mathrm{V} & \text { Class } \\ 1 & 148 & 57 & 114 & 1 \\ 2 & 147 & 57 & 122 & 1 \\ 3 & 148 & 59 & 125 & 1 \\ 4 & 149 & 58 & 121 & 1 \\ 5 & 148 & 57 & 131 & 1 \\ 6 & 149 & 57 & 126 & 1 \\ 7 & 150 & 55 & 140 & 1 \\ 8 & 150 & 58 & 134 & 1 \\ 9 & 140 & 49 & 110 & 1 \\ 10 & 148 & 58 & 118 & 1 \\ 11 & 149 & 55 & 120 & 1 \\ 12 & 147 & 55 & 115 & 1 \\ 13 & 150 & 62 & 118 & 1 \\ 14 & 140 & 51 & 106 & 1 \\ 15 & 143 & 51 & 98 & 1 \\ 16 & 147 & 69 & 121 & 1 \\ 17 & 148 & 67 & 124 & 1 \\ 18 & 147 & 65 & 135 & 1 \\ 19 & 151 & 64 & 139 & 1 \\ 20 & 151 & 69 & 134 & 1 \\ 21 & 151 & 64 & 140 & 1 \\ 22 & 149 & 65 & 133 & 1 \\ 23 & 152 & 71 & 130 & 1 \\ 24 & 152 & 63 & 138 & 1 \\ 25 & 148 & 63 & 130 & 1 \\ 26 & 149 & 67 & 135 & 1 \\ 27 & 151 & 69 & 121 & 1 \\ 28 & 148 & 68 & 123 & 1 \\ 29 & 152 & 69 & 124 & 1\end{array}$




\begin{tabular}{|c|c|c|c|c|c|c|c|c|}
\hline 30 & 150 & 62 & 140 & 1 & 79 & 151 & 58 & 129 \\
\hline 31 & 150 & 61 & 131 & 1 & 80 & 149 & 55 & 118 \\
\hline 32 & 155 & 62 & 140 & 1 & 81 & 150 & 57 & 117 \\
\hline 33 & 151 & 60 & 136 & 1 & 82 & 150 & 56 & 119 \\
\hline 34 & 154 & 62 & 136 & 1 & 83 & 151 & 61 & 124 \\
\hline 35 & 151 & 61 & 136 & 1 & 84 & 150 & 58 & 116 \\
\hline 36 & 150 & 60 & 126 & 1 & 85 & 150 & 57 & 111 \\
\hline 37 & 149 & 59 & 133 & 1 & 86 & 150 & 58 & 120 \\
\hline 38 & 151 & 61 & 123 & 1 & 87 & 148 & 59 & 110 \\
\hline 39 & 153 & 64 & 132 & 1 & 88 & 138 & 51 & 94 \\
\hline 40 & 149 & 60 & 121 & 1 & 89 & 127 & 52 & 138 \\
\hline 41 & 151 & 62 & 129 & 1 & 90 & 141 & 45 & 164 \\
\hline 42 & 149 & 58 & 103 & 1 & 91 & 134 & 51 & 134 \\
\hline 43 & 154 & 65 & 123 & 1 & 92 & 141 & 46 & 151 \\
\hline 44 & 145 & 57 & 103 & 1 & 93 & 132 & 46 & 133 \\
\hline 45 & 151 & 61 & 142 & 1 & 94 & 131 & 54 & 134 \\
\hline 46 & 148 & 61 & 136 & 1 & 95 & 131 & 51 & 134 \\
\hline 47 & 146 & 60 & 124 & 1 & 96 & 133 & 47 & 134 \\
\hline 48 & 150 & 63 & 129 & 1 & 97 & 130 & 50 & 132 \\
\hline 49 & 152 & 57 & 149 & 1 & 98 & 127 & 53 & 120 \\
\hline 50 & 152 & 58 & 144 & 1 & 99 & 128 & 46 & 173 \\
\hline 51 & 154 & 62 & 146 & 1 & 100 & 137 & 47 & 148 \\
\hline 52 & 150 & 58 & 144 & 1 & 1 & 127 & 52 & 138 \\
\hline 53 & 149 & 58 & 128 & 1 & 2 & 141 & 45 & 164 \\
\hline 54 & 150 & 60 & 129 & 1 & 3 & 134 & 51 & 134 \\
\hline 55 & 153 & 63 & 143 & 1 & 4 & 141 & 46 & 151 \\
\hline 56 & 146 & 58 & 119 & 1 & 5 & 132 & 46 & 133 \\
\hline 57 & 152 & 62 & 128 & 1 & 6 & 131 & 54 & 134 \\
\hline 58 & 146 & 57 & 117 & 1 & 7 & 131 & 51 & 134 \\
\hline 59 & 145 & 56 & 115 & 1 & 8 & 133 & 47 & 134 \\
\hline 60 & 153 & 63 & 132 & 1 & 9 & 130 & 50 & 132 \\
\hline 61 & 152 & 60 & 129 & 1 & 10 & 127 & 53 & 120 \\
\hline 62 & 151 & 61 & 123 & 1 & 11 & 128 & 46 & 173 \\
\hline 63 & 150 & 56 & 113 & 1 & 12 & 137 & 47 & 148 \\
\hline 64 & 151 & 58 & 129 & 1 & 13 & 132 & 48 & 165 \\
\hline 65 & 149 & 55 & 118 & 1 & 14 & 138 & 46 & 144 \\
\hline 66 & 150 & 57 & 117 & 1 & 15 & 130 & 48 & 156 \\
\hline 67 & 150 & 56 & 119 & 1 & 16 & 125 & 48 & 121 \\
\hline 68 & 151 & 61 & 124 & 1 & 17 & 134 & 49 & 150 \\
\hline 69 & 150 & 58 & 116 & 1 & 18 & 134 & 49 & 137 \\
\hline 70 & 150 & 57 & 111 & 1 & 19 & 110 & 51 & 135 \\
\hline 71 & 150 & 58 & 120 & 1 & 20 & 134 & 46 & 135 \\
\hline 72 & 148 & 59 & 110 & 1 & 21 & 126 & 43 & 166 \\
\hline 73 & 138 & 51 & 94 & 1 & 22 & 125 & 46 & 148 \\
\hline 74 & 151 & 62 & 114 & 1 & 23 & 132 & 47 & 139 \\
\hline 75 & 153 & 63 & 132 & 1 & 24 & 120 & 49 & 152 \\
\hline 76 & 152 & 60 & 129 & 1 & 25 & 101 & 51 & 146 \\
\hline 77 & 151 & 61 & 123 & 1 & 26 & 121 & 62 & 117 \\
\hline 78 & 150 & 56 & 113 & 1 & 27 & 135 & 47 & 144 \\
\hline
\end{tabular}


Larry B. de Guzman, International Journal of Emerging Trends in Engineering Research, 8(8), August 2020,4350 - 4356

\begin{tabular}{|c|c|c|c|c|c|c|c|c|}
\hline 28 & 123 & 41 & 177 & 2 & 77 & 123 & 52 & 165 \\
\hline 29 & 134 & 45 & 142 & 2 & 78 & 142 & 49 & 145 \\
\hline 30 & 133 & 43 & 174 & 2 & 79 & 135 & 55 & 123 \\
\hline 31 & 127 & 47 & 149 & 2 & 80 & 137 & 52 & 169 \\
\hline 32 & 132 & 46 & 153 & 2 & 81 & 140 & 52 & 141 \\
\hline 33 & 133 & 50 & 137 & 2 & 82 & 144 & 52 & 148 \\
\hline 34 & 125 & 55 & 116 & 2 & 83 & 141 & 49 & 151 \\
\hline 35 & 126 & 53 & 119 & 2 & 84 & 140 & 50 & 141 \\
\hline 36 & 126 & 47 & 142 & 2 & 85 & 130 & 55 & 120 \\
\hline 37 & 100 & 46 & 173 & 2 & 86 & 142 & 51 & 148 \\
\hline 38 & 129 & 49 & 136 & 2 & 87 & 128 & 50 & 157 \\
\hline 39 & 127 & 46 & 145 & 2 & 88 & 122 & 46 & 177 \\
\hline 40 & 109 & 54 & 159 & 2 & 89 & 129 & 48 & 161 \\
\hline 41 & 104 & 44 & 176 & 2 & 90 & 140 & 54 & 146 \\
\hline 42 & 127 & 48 & 136 & 2 & 91 & 138 & 53 & 153 \\
\hline 43 & 134 & 45 & 130 & 2 & 92 & 136 & 54 & 159 \\
\hline 44 & 121 & 49 & 125 & 2 & 93 & 144 & 55 & 138 \\
\hline 45 & 120 & 48 & 115 & 2 & 94 & 130 & 71 & 116 \\
\hline 46 & 121 & 50 & 147 & 2 & 95 & 134 & 53 & 142 \\
\hline 47 & 120 & 50 & 161 & 2 & 96 & 138 & 51 & 141 \\
\hline 48 & 138 & 44 & 146 & 2 & 97 & 131 & 59 & 136 \\
\hline 49 & 123 & 50 & 126 & 2 & 98 & 140 & 51 & 155 \\
\hline 50 & 111 & 52 & 154 & 2 & 99 & 119 & 58 & 110 \\
\hline 51 & 136 & 57 & 131 & 2 & 100 & 139 & 53 & 135 \\
\hline 52 & 135 & 53 & 132 & 2 & & & & \\
\hline 53 & 144 & 53 & 159 & 2 & & & & \\
\hline 54 & 135 & 59 & 132 & 2 & & & & \\
\hline 55 & 143 & 52 & 155 & 2 & & & & \\
\hline 56 & 144 & 56 & 142 & 2 & & & & \\
\hline 57 & 131 & 55 & 121 & 2 & & & & \\
\hline 58 & 147 & 51 & 163 & 2 & & & & \\
\hline 59 & 142 & 48 & 168 & 2 & & & & \\
\hline 60 & 142 & 51 & 160 & 2 & & & & \\
\hline 61 & 140 & 52 & 152 & 2 & & & & \\
\hline 62 & 140 & 55 & 142 & 2 & & & & \\
\hline 63 & 139 & 50 & 135 & 2 & & & & \\
\hline 64 & 137 & 53 & 134 & 2 & & & & \\
\hline 65 & 130 & 58 & 122 & 2 & & & & \\
\hline 66 & 144 & 45 & 172 & 2 & & & & \\
\hline 67 & 135 & 51 & 160 & 2 & & & & \\
\hline 68 & 127 & 53 & 170 & 2 & & & & \\
\hline 69 & 142 & 50 & 149 & 2 & & & & \\
\hline 70 & 137 & 54 & 157 & 2 & & & & \\
\hline 71 & 138 & 53 & 134 & 2 & & & & \\
\hline 72 & 131 & 63 & 120 & 2 & & & & \\
\hline 73 & 144 & 52 & 151 & 2 & & & & \\
\hline 74 & 139 & 46 & 169 & 2 & & & & \\
\hline 75 & 141 & 52 & 151 & 2 & & & & \\
\hline 76 & 146 & 43 & 164 & 2 & & & & \\
\hline
\end{tabular}

